\title{
Transportation Problem of LPP Involving Probability Density Function
}

https://doi.org/10.3991/ijes.v7i1.9909

\author{
Mohammad Rashid Hussain $\left.{ }^{(}\right)$, Mohammed Qayyum \\ King Khalid University, Abha, Saudi Arabia \\ humohammad@kku.edu.sa \\ Md Equebal Hussain \\ Suresh Gyan Vihar University, Jaipur, India
}

\begin{abstract}
In Linear Programming Problem (LPP), Transportation Problem (TP) is an application which is used to optimize through the probability density function of statistical approach. The main objective of this paper is to reduce complexity in Maximization problem of LPP, by fulfilling the relation between the objective function and constraints with the largest value. Here, we used nonnegative integer and complex number of linear combination of form xme $\lambda x$. It has been decided with reasonably great probability, decision region, fundamental probabilities and Laplace Transform (LT). To obtain proposed results we applied probability density function over transportation problem. According to our proposed method we implemented mathematical model through the probability density function of statistical tools. Categorically, probability density function is an approach in our proposed method to obtain the feasible solution of transportation problem, which perform better than the existing methods.
\end{abstract}

Keywords - Transportation Problem (TP), Laplace Transform (LT), Linear Programming Problem (LPP), Probability Density Function (PDF)

\section{Introduction}

The joint density is known of random coefficient with Linear Programming Problem (LPP) whose commutative distribution function is optimal. The optimum point of a LPP always lies on one of the corner points of the graphs feasible region. If the optimum point of LPP does not lie on either $\mathrm{x}$ or $\mathrm{y}$ axis, we can find its coordinates by drawing vertices and horizontal lines from the optimum point towards the two axis. The assumption of planner is to select the optimum one " $\alpha$ " is denoted as optimum solution of objective function in respect of operation " $\beta$ ". In linear program vector " $t$ " which is of optimum function is considered as random variable. As per the nature of problem, decide the objective function of LPP which is either of maximization or minimizations, then set the target " $T$ ". The condition of maximization problem with the most probable chance should be reach with $\alpha(t) \geq T$ 
with the cumulative distribution. The objective is to reach up to the optimality means, some of the statistical approach like mean $\mathrm{E}(\mathrm{x})=\int_{0}^{\infty} x f(x) d x, \mathrm{x}>0$ and variance $\mathrm{V}(\mathrm{x})$ $=\mathrm{E}\left(\mathrm{x}^{2}\right)-[\mathrm{E}(\mathrm{x})]^{2}$ of objective function should be present with same context. In [1], [3], a single random variable under the same restrictions this problem was solved for a linear function with a coefficient of objective function or the resource vector or both. In Transportation problem of LPP, finite number of random variables are required in [2], [7], [4], [8], [9], Random costs, consumption and some application of programming to planning have been introduced, in [6],[5] the concept of stochastically and non-stochastically technological matrix concept have introduced, for all the above references are generalized for finite number of random variables for LPP. The problem which is frequently used in practice is important to obtain the information for particular types of problems. A finite number of random variables needed to decide for LPP to set its coefficients. The concept of LPP which introduced earlier by the above referred authors with their great efforts, to provide the platform to researchers of respective field are exemplary. Finally, we reach to conclude the result of given approach and proceed with some additional concept which will be more beneficial and fruitful for the author who are working over this concepts. In Section 1; Fundamental concept of probabilities and earlier result have summarized and obtained a new result which is optimum. In Section 2; the concept of Laplace Transform (LT) of finite $\mathrm{x}, \mathrm{f}(\mathrm{x})$;

$\mathcal{L}\{\mathrm{f}(\mathrm{x}) ; \mathrm{s}\}=\mathrm{f}^{*}(\mathrm{~s})=\int_{-\infty}^{\infty} e^{-s x} f(x) d x$ have introduced to apply over the TP with the random consumption of negative exponential for optimum solution by using probability density function (PDF).

\section{Mathematical Notations}

In fundamental concepts and properties of Matrices and probabilities are considered to implement in introduce approach to achieve a new result, which will reduce the complexity over existing concept. Here, "A" is denoted as a matrix A and its transpose $\mathrm{A}^{\mathrm{T}}$. The rank of matrix is another useful factors of elementary transformation and for the solution of system of non-homogeneous linear equations. Row of a matrix is denoted as $R_{i}$ and $R_{j}$, while finding the $\rho(A) \rightarrow$ Rank of $A$, matrix will use their elementary transformation $R_{i} \leftrightarrow R_{j}, R_{i} \leftrightarrow k R_{i}$, and $R_{i} \leftrightarrow k_{j}+R_{i}$, to change in echelon form, $\rho(\mathrm{A})=$ number of non-zero rows in the echelon for (every upper triangular form is already in echelon form but every echelon form need not be a upper triangular form), $\alpha(t)$ represent as $\alpha$ for real valued function of $t \in T$. There are different approaches of probabilities: classical approaches (finite), empirical approaches (infinite) and Axiomatic approach, Product rule of events A and B. P $(\mathrm{AB})=\mathrm{P}(\mathrm{A} \cup \mathrm{B})-\mathrm{P}(\mathrm{A}) \cdot \mathrm{P}(\mathrm{B} / \mathrm{A}) ; \quad \mathrm{P}(\mathrm{A})>0 \quad$ for compound probabilities. $\mathrm{P}(\mathrm{B} \cup \mathrm{A})=\mathrm{P}(\mathrm{B}) \cdot \mathrm{P}(\mathrm{A} / \mathrm{B}), \mathrm{P}(\mathrm{B})>0$ for conditional probabilities, when $\mathrm{A}$ and $\mathrm{B}$ are independent events, then $\mathrm{P}(\mathrm{A} \cup \mathrm{B})=\mathrm{P}(\mathrm{A}) \cdot \mathrm{P}(\mathrm{B}) ; \quad \mathrm{P}(\mathrm{A})=(x+a)^{n}=\sum_{i=1}^{n} P\left(E_{i}\right) P\left(\frac{A}{E_{I}}\right)$ Where $\mathrm{E}_{1}, \mathrm{E}_{2}, \mathrm{E}_{\mathrm{n}}$ are the disjoint events $\mathrm{P}\left(E_{i}\right) \neq 0$ such that "A" is arbitrary events $\mathrm{P}(\mathrm{A})>0$ which is the subset of Union $U_{i=1}^{n} E_{i}$. 
We are given an m-vector, $\mathrm{b}=\left(\mathrm{b}_{1}, \mathrm{~b}_{2}, \mathrm{~b}_{\mathrm{m}}\right)^{\mathrm{T}}$, $\mathrm{n}$-vector, $\left.\mathrm{c}=\mathrm{c}_{1}, \mathrm{c}_{2} \ldots \mathrm{c}_{\mathrm{n}}\right)^{\mathrm{T}}$ and an mxn matrix.

$$
A=\left(\begin{array}{cccc}
a_{11} & a_{12} & \cdots & a_{1 n} \\
\vdots & \ddots & & \vdots \\
a_{m 1} & a_{m 2} & \cdots & a_{m n}
\end{array}\right)
$$

\section{$3 \quad$ Terminology}

\subsection{Feasible Vector}

Maximized or Minimized functions are called objective function. To satisfy the corresponding constraints, a vector is said to be feasible. The set of constraints are called the set of feasible vectors.

- LPP->feasible->constraints set is not empty.

- LPP->Infeasible ->constraints set is empty.

- There are three possibilities for LPP.

- It may be bounded feasible.

- It may be unbounded feasible.

- It may be infeasible.

A feasible vector in which objective function achieve the value is called optimal.

\subsection{LPP Converted to Standard Form}

To change minimize problem to maximize problem, multiply the objective function by -1 ; similarly, if any problem constraints have negative on right side, multiply both side by -1 if the constraint.

Minimum Problem $\sum_{j=1}^{n} a_{i j} x_{j} \geq b_{i}$ then

Maximum problem $\sum_{j=1}^{n}\left(-a_{i j}\right) x_{j} \leq-b_{i}$

For equality constraints: - Remove one constraint and one variable from the problem by substituting $\sum_{j=1}^{n} a_{i j} x_{j}=b_{i}$ for some $\mathrm{x}_{\mathrm{j}}$ in which $\mathrm{a}_{\mathrm{ij}} \neq 0$.

\subsection{Maximize and Minimize problem of LPP}

Find an n-vector $\mathrm{x}=\left(\mathrm{x}_{\mathrm{i}}\right)^{\mathrm{T}}$,

$\operatorname{Max}(\mathrm{z})=\mathrm{c}_{\mathrm{i}}^{\mathrm{T}} \mathrm{x}_{\mathrm{i}}(\mathrm{i}=1,2 \mathrm{n})$

$\mathrm{X}=\{\mathrm{x} \mid \mathrm{Ax} \leq \mathrm{b}, \mathrm{x} \geq 0\}, \mathrm{X}_{\mathrm{t}}=\{\mathrm{x} \mid \mathrm{Ax} \leq \mathrm{b}(\mathrm{t}), \mathrm{x} \geq 0\}$

Here, $t$ is a random $r$-vector with probability density function $f\left(t_{1}, t_{2}, t_{r}\right)$ continuous and positive for $\mathrm{t} \in \mathrm{T}$, so, $\mathrm{X}$ is nonvoid and bounded.

Coefficient matrix: $A=($ aij)mxn; $i=1,2 ., n ; j=1,2, m$. 


$$
\begin{aligned}
& \text { Variable vector: } \mathrm{x}=\left(\begin{array}{c}
x_{1} \\
\cdot \\
x_{n}
\end{array}\right)_{n x 1}=\left(x_{i}\right)_{n x 1} ; \mathrm{x} \in \mathrm{X} \\
& \text { Constant Colum vector: } \mathrm{b}=\left(\begin{array}{c}
b_{1} \\
\cdot \\
b_{m}
\end{array}\right)_{m x 1}=\left(b_{i}\right)_{m x 1}
\end{aligned}
$$

Here, " $\mathrm{A}$ " is an $\mathrm{mxn}(\mathrm{m} \leq \mathrm{n})$ matrix of rank $\mathrm{m}$; $\mathrm{x}$ and $\mathrm{c}$ are $\mathrm{n}$-vector; $\mathrm{b}$ is an $\mathrm{m}$ vector.

Minimize problem of LPP, Apply terminology 2(i) to change minimize to maximize.

\subsection{Properties of Rank of Matrix}

To find the solution of the problem of LPP by applying the properties of rank of matrix in above introduced part $C$. of $n$ number of variables.

Let $\rho(A)$ : Rank of $A=r ; \rho(A \quad b)=$ : Rank of augment matrix $\left(\begin{array}{ll}A & b\end{array}\right)=r$ '

- Case I: if $r=r^{\prime}=n$; solution will be unique.

- Case II: if $r=r^{\prime}<n$; infinite number of solutions.

- Case III: if $r \neq r^{\prime}$; inconsistent (no solution).

\section{Dual General to Maximum Standard Problem}

If a dual general maximum problem is transformed to standard maximum problem.

- Replace each equality constraints $\sum_{j} a_{i j} x_{j}=$ bi by two inequality constraints $\sum_{j} a_{i j} x_{j} \leq$ bi and $\sum_{j}\left(-a_{i j}\right) x_{j} \leq$-bi

- Replace each unrestricted variable $x j$ by the difference of two non-negative variables. $x j=x j$ '-xj" with $x j ' \geq 0$ and $x j " \geq 0$.

- Repeat step ii. For minimum problem.

Let $\mathrm{c}$ and $\mathrm{x}$ are $\mathrm{n}$-vectors, $\mathrm{b}$ and $\mathrm{y}$ are $\mathrm{m}$-vectors, and $\mathrm{A}$ is an mxn matrix; we assume $m \geq 1$ and $n \geq 1$

\begin{tabular}{|c|c|}
\hline Primal & Dual \\
\hline $\begin{array}{l}\text { Max } c^{T} x \\
\text { Subject to: Ax } \leq b \\
x \geq 0\end{array}$ & $\begin{array}{l}\text { Min } y^{T} b \\
\text { Subject to: } y^{T} A \geq C^{T} \\
y \geq 0\end{array}$ \\
\hline
\end{tabular}

Table 1. Primal and dual 
Table 2. Representation of dual problem

\begin{tabular}{|c|c|c|c|c|c|}
\hline & $\mathbf{x}_{\mathbf{1}}$ & $\mathbf{x}_{\mathbf{2}}$ & & $\mathbf{x}_{\mathbf{n}}$ & \\
\hline $\mathrm{y}_{1}$ & $\mathrm{a}_{11}$ & $\mathrm{a}_{12}$ & & $\mathrm{a}_{1 \mathrm{n}}$ & $\leq \mathrm{b}_{1}$ \\
\hline $\mathrm{y}_{2}$ & $\mathrm{a}_{21}$ & $\mathrm{a}_{22}$ & & $\mathrm{a}_{2 \mathrm{n}}$ & $\leq \mathrm{b}_{2}$ \\
\hline & & & & & \\
\hline $\mathrm{y}_{\mathrm{m}}$ & $\mathrm{a}_{\mathrm{m} 1}$ & $\mathrm{a}_{\mathrm{m} 2}$ & & $\mathrm{a}_{\mathrm{mn}}$ & $\leq \mathrm{b}_{\mathrm{m}}$ \\
\hline & $\mathrm{c}_{1}$ & $\mathrm{c}_{2}$ & & $\geq \mathrm{c}_{\mathrm{n}}$ & \\
\hline
\end{tabular}

If $\mathrm{x}$ and $\mathrm{y}$ are feasible for cTx and its dual $\mathrm{yTb}$ then, $\mathrm{cTx} \leq \mathrm{yTb}$. If a problem and its dual are feasible, then both are bounded feasible. So both are optimal for their respective problem, then equilibrium condition exist. If $x^{*}$ and $y^{*}$ are the feasible vectors for maximum problem and its dual respectively. Then $\mathrm{x}^{*}$ and $\mathrm{y}^{*}$ are optimal if and only if,

$$
\begin{aligned}
& \mathrm{yi}^{*}=0 \text { for all } \mathrm{i} \text { for which } \sum_{\mathrm{j=1}}^{\mathrm{n}}\left(\mathrm{a}_{\mathrm{ij}}\right) \mathrm{x}_{\mathrm{j}}{ }^{*}<\mathrm{b}_{\mathrm{i}} \text { and } \\
& \mathrm{xj}^{*}=0 \text { for all } \mathrm{j} \text { for which } \sum_{\mathrm{i}=1}^{\mathrm{m}} \mathrm{y}_{\mathrm{i}}{ }^{*} \mathrm{a}_{\mathrm{ij}}>\mathrm{c}_{\mathrm{j}}, \\
& \text { implies } \sum_{\substack{1 \leq \mathrm{i} \leq \mathrm{m} \\
1 \leq \mathrm{j} \leq \mathrm{n}}} \mathrm{y}_{\mathrm{i}}{ }^{\mathrm{n}} \mathrm{a}_{\mathrm{ij}} \mathrm{x}_{\mathrm{j}}^{*}=\sum_{\mathrm{j}=1}^{\mathrm{n}} \mathrm{c}_{\mathrm{j}} \mathrm{x}_{\mathrm{j}}{ }^{*}
\end{aligned}
$$

Such that $\mathrm{x}^{*}$ and $\mathrm{y}^{*}$ are optimal,

$$
\text { Hence } \sum_{\mathrm{j}=1}^{\mathrm{n}}\left(\mathrm{c}_{\mathrm{j}}-\sum_{\mathrm{i}=1}^{\mathrm{m}} \mathrm{y}_{\mathrm{i}}{ }^{*} \mathrm{a}_{\mathrm{ij}}\right) \mathrm{x}_{\mathrm{j}}{ }^{*}=0
$$

Linear inequalities is describe $\mathrm{Rl}(1 \leq \mathrm{l} \leq \mathrm{q})$ as decision regions, $\mathrm{xl}$ is a set of basic solution with base $\mathrm{Bl}$; $(\mathrm{r}+1)$ - vectors $\delta \mathrm{l}=\delta 01, \delta 11$, $\delta \mathrm{rl})$ such that $\mathrm{t} \in \mathrm{Rl}=>\alpha(\mathrm{t})=\mathrm{cTx}(\mathrm{t}) \mathrm{xl}=$ $\delta 01+\delta 11$ t $1+. \delta$ rltr

The matrix $\left(\left|\delta_{k}{ }^{l}\right|, 0 \leq k \leq r, 1 \leq l \leq q\right)$ is a matrix of optima and $\mathrm{pl}$ are the fundamental probabilities of $\mathrm{X}=\{\mathrm{x} \mid \mathrm{Ax}=\mathrm{b}, \mathrm{x} \geq 0\}$ corresponding result for $\mathrm{Xt}=$ $\{\mathrm{x} \mid \mathrm{Ax}=\mathrm{b}(\mathrm{t}), \mathrm{x} \geq 0\}$ and random variable $\alpha(\mathrm{t})=\min _{x \in X_{t}} \mathrm{c}^{T} x(t)$

Let $\mathrm{Fl}(\mathrm{x})$ : cumulative distribution function of $\alpha \mathrm{l}(\mathrm{t})$.

$\mathrm{fl}(\mathrm{x})$ : Probability density function of $\alpha \mathrm{l}(\mathrm{t})$.

$\operatorname{pl}(1 \leq \mathrm{l} \leq \mathrm{q})$ is the fundamental probability of the stochastic LP. As we know,

The relation between cumulative distribution function and probability density function of the optimum $\alpha(\mathrm{t})=\alpha \mathrm{l}(\mathrm{t})(\mathrm{t} \in \mathrm{Sl})$, so the function $\alpha \mathrm{l}(\mathrm{t})$ and the set $\mathrm{Sl}$; $\mathrm{P}(\mathrm{Si})=\mathrm{pi}$, this is valid for Linear programming of $\mathrm{Xt}=\{\mathrm{x} \mid \mathrm{Ax}=\mathrm{b}(\mathrm{t}), \mathrm{x} \geq 0\}$.

The random variables $\alpha \mathrm{l}(\mathrm{t})$ are non-negative and $\mathrm{f}_{\mathrm{i}}{ }^{*}(\mathrm{~s})$ is the Laplace transform of probability density function of random variable $\alpha \mathrm{l}(\mathrm{t}),(1 \leq \mathrm{l} \leq \mathrm{q})$ and $\mathrm{f}_{\alpha}{ }^{*}(\mathrm{~s})$ is the LT of probality density function of the optimum, then $\mathrm{f}_{\alpha}{ }^{*}(\mathrm{~s})=\sum_{\mathrm{l}=1}^{\mathrm{q}} \mathrm{p}_{\mathrm{l}} \mathrm{f}_{\mathrm{l}}{ }^{*}(\mathrm{~s})$ 


\section{Transportation Problem}

The problem is to find numbers yij $(1<\mathrm{i}<\mathrm{m}, 1<\mathrm{j}<\mathrm{n}+1)$, to minimize the total transportation cost restricted by $\sum_{\substack{1 \leq i \\ 1 \leq j}} y_{i j} b_{i j}=\sum_{1 \leq i \leq m} y_{i j} b_{i j}$.

The supply for the non-negativity constraints yij $\geq 0$ for all $\mathrm{i}$ and $\mathrm{j} ; \sum_{j=1}^{n+1}\left(y_{i j}\right) \leq s_{i}$ for $\mathrm{i}=1,2, \mathrm{~m}$

The demand constraints, $\sum_{i=1}^{m}\left(y_{i j}\right) \geq d_{j}$ for $\mathrm{j}=1,2, \mathrm{n}+1$, where si, dj and bij are given non-negative numbers.

The transportation problem is not feasible unless supply is at least as great as demand.

$$
\sum_{i=1}^{m} s_{i} \geq \sum_{j=1}^{n+1} d_{j}
$$

The minimum cost can be defined for any $\mathrm{t} \in \mathrm{T}$

$$
\alpha(\mathrm{t})=\min (\mathrm{yij}) \sum_{1 \leq j \leq n+1} y_{i j} b_{i j},(\mathrm{t} \in \mathrm{T}) .
$$

The restriction of standard transportation problem, the realization of the random variables are known before choosing the transportation plan, there are I ports, p1,p2, pi that supply a certain commodity, and there are $\mathrm{j}$ markets, $\mathrm{m} 1, \mathrm{~m} 2, \ldots . \mathrm{mj}$, to which this commodity must be shipped. Port pi possesses an amount s1....i of the commodity $(1,2, i)$ and market mj must receive the amount $\mathrm{d} 1,2, \mathrm{j}$ let bij be the cost of transporting one unit of the commodity from port pi to market $\mathrm{mj}$. The problem is to meet the market requirements at minimum transportation cost. So, it is assumed that we cannot send a negative amount from pi to $\mathrm{mj}$, we have $y \mathrm{ij} \geq 0$ for $\mathrm{i}, \mathrm{j}$, under the assumption, simple algorithm is required to make the total demand is equal to total supply. To make the assumption positive by the device of aiding to the problem a dummy market, i.e. dump, which fulfil the requirement to make total demand equal to total supply, such that transportation costs to the dump are zero.

$$
\sum_{i=1}^{m} s_{i}=\sum_{j=1}^{n+1} d_{j}
$$

So, it is sufficient to find feasible vectors, yij, ui and vj, that satisfy the equilibrium condition which reduce for all $\mathrm{i}$ and $\mathrm{j}$; yij $>0$ implies that $\mathrm{vj-ui=bij}$; now, this problem can be easily solve by simplex method, the simplex tableau for this problem involves an ij by $i+j$ constraint matrix. For this types of problem, it is easy to implement transportation problem instead of simplex method, because it may describe easily in terms of $i$ and $j$ transportation array. 
Table 3. Representation of Transportation array

\begin{tabular}{|c|c|c|c|c|}
\hline & m1 & $\mathrm{m} 2$ & $\mathbf{m j}$ & \\
\hline $\mathrm{p} 1$ & $\begin{array}{l}\text { b11 } \\
\text { y11 }\end{array}$ & $\begin{array}{l}\mathrm{b} 12 \\
\mathrm{y} 12\end{array}$ & $\begin{array}{l}\mathrm{b} 1 \mathrm{j} \\
\mathrm{y} 1 \mathrm{j}\end{array}$ & s1 \\
\hline p2 & $\begin{array}{l}\mathrm{b} 21 \\
\mathrm{y} 21\end{array}$ & $\begin{array}{l}\mathrm{b} 22 \\
\mathrm{y} 22\end{array}$ & $\begin{array}{l}b 2 j \\
y 2 j\end{array}$ & s2 \\
\hline \multirow[t]{2}{*}{ pi } & $\begin{array}{l}\text { bi1 } \\
\text { yi1 }\end{array}$ & $\begin{array}{l}\text { bi2 } \\
\text { yi2 }\end{array}$ & $\begin{array}{l}\text { bij } \\
\text { yij }\end{array}$ & si \\
\hline & $\mathrm{d} 1$ & $\mathrm{~d} 2$ & $\mathrm{dj}$ & \\
\hline
\end{tabular}

The algorithm, which consists three parts:

- Find a basic feasible shipping schedule yij.

- Test for optimality

- If the test fails, find an improved basic feasible shipping schedule, and above.

The main aim of transportation problem is to find the distribution of minimum total costs with its mean value and variance, by applying probability density function over number $\alpha_{\mathrm{j}}$ which is positive.

$\phi_{j}(x)=\left\{\lambda, e^{-\alpha, x}\right.$ if $x \geq 0$ and o if $x<0$ for $\left.i \leq j \leq n\right\}$;

As we know, if $l_{i}(1 \leq i \leq d)$ are independent non-negative random variables with probability density function

$\phi_{\mathrm{i}}(\mathrm{x}), 0 \leq \mathrm{i} \leq \mathrm{d}$.

$f_{l}^{*}(s)$ is the LT of the probability density function of random variable $\alpha_{1}(\mathrm{t})$ where $1 \leq \mathrm{l} \leq \mathrm{q}$ and $f_{\alpha}{ }^{*}(s)$ is the LT of probability density function of optimum:

$f_{\alpha}^{*}(s)=\sum_{l=1}^{q} p_{l} f_{l}^{*}(s)$.

By applying the above theorem, we can obtain

$\mathcal{L}\left(\alpha, \mathrm{e}^{-\alpha, \mathrm{x}}, \mathrm{s}\right)=\int_{0}^{\infty} \alpha, e^{-\alpha, x} e^{-s z} d x=\alpha_{j} /\left(\alpha_{j}+s\right) ;$

By applying elementary properties of LT of

$\mathrm{f}_{\alpha}(\mathrm{x})=\sum_{1 \leq i \leq q} \alpha_{i j} A_{i j} \psi_{i j}(x)$; Where, $\psi_{i j}(x)=e^{-\alpha_{i j}\left(x-\lambda_{0}{ }^{i}\right)}$ if $\mathrm{x} \geq \lambda_{0}{ }^{i}$, otherwise 0 . $1 \leq j \leq n$

$\lambda_{r}{ }^{i}$ is $(\mathrm{r}+1)$ vectors, $\mathrm{t}=\left(\mathrm{t}_{1}, \mathrm{t}_{2}, \mathrm{t}_{\mathrm{r}}\right)$ a random vector with value in $\mathrm{R}_{\mathrm{r}}$, Problem $\mathrm{T}$ is an $\mathrm{r}$ dimensional interval.

We obtained probability density function of optimum

$$
\mathrm{F}_{\alpha}(\mathrm{x})=\sum_{\substack{1 \leq i \leq q \\ 1 \leq j \leq n}} A_{i j}\left(1-B_{i j} e^{-\alpha_{i j} x}\right) \text { where } B_{i j}=e^{\lambda_{0}{ }^{i \alpha_{i j}}} \& \mathrm{~F}(\infty)=1 \text {, }
$$

The obtained results are useful to implement over transportation problem to conclude our approach.

\section{Conclusion}

The concept of this paper, to use the non-negative integer and complex number of linear combination of form $\mathrm{xme} \lambda \mathrm{x}$ which is a probability density function of minimum total transportation costs. These are used and implemented in our proposed 
approach to reduce the complexity and improve the accuracy of result with the distribution of continuous non-negative random variables. For this, the LT of the probability density function is a rational function of ' $\mathrm{s}$ ' having arbitrary mean and any coefficient variation between 1 and $+\infty$. The introduced approach can be used to solve different Linear Programming Problems to obtain probability density function of optimum which perform better than the existing methods that is frequently refer to a transportation problems.

\section{$7 \quad$ References}

[1] G. MIHOC. Some clarifications concerning the application of linear programming (Rumanian). Rev. Statist. 12 (1959), 13-18.

[2] B. BEREANU. Stochastic transportation problem I. Random costs (Rumanian). Corn. Acad. R.P.R. 13 (1963), 325-331.

[3] B. BEREANU. On stochastic linear programming I. Distribution problems: a single random variable. Rev. Math. Pures Appl. 13 (1963), 683-697.

[4] B. BEREANU. Some applications of stochastic programming to planning (Rumanian). Proc. Sci. Statist. Conf. pp. 95-107, D.C.S., Bucharest, 1963.B. BEREANU. On stochastic linear programming. Distribution problems: Stochastical technological matrix. (To appear).

[5] B. BEREANU. On stochastic linear programming II. Distribution problems: Nonstochastical technological matrix. (To appear).

[6] B. BEREANU. Stochastic transportation problem II. Random consumptions (Rumanian). Corn. Acad. R.P.R. 13 (1963), 333-337.

[7] A. Shapiro, D. Dentcheva, and A. Ruszczynski, ' Lectures on Stochastic Programming: Modeling and Theory, SIAM, 2009. https://doi.org/10.1137/1.9780898718751

[8] Afrooz Ansaripour, Adriana Mata, "Some Explicit Results for the Distribution Problem of Stochastic Linear Programming" Open Journal of Optimization, 2016, 5, 140-162, Scientific research publishing https://doi.org/10.4236/ojop.2016.54014

[9] Deshabrata Roy Mahapatra, Multi-choice stochastic transportation problem involving Weibull distribution, An International Journal of Optimization and Control: Theories \& Applications Vol.4, No.1, pp.45-55 (2014) at IJOCTA ISSN:2146-0957 eISSN:2146-5703 http://www.ijocta.com https://doi.org/10.11121/ijocta.01.2014.00154

[10] L. T. Santos , F. A. Dorini , M. C. C. Cunha, The Probability Density Function to the Random Linear Transport Equation, Preprint submitted to Elsevier Science, 2008

[11] A. Papoulis, Probability, Random Variables, and Stochastic Processes, 2nd Edition, McGraw-Hill, Inc., New York, 1984

[12] Mahapatra, D.R., Roy, S.K. and Biswal, M.P., Computation of multi-objective stochastic transportation problem involving normal distribution with joint constraints. The Journal of Fuzzy Mathematics. 19(4), 865-876 (2011).

[13] Acharya, S and Acharya, M.M., Generalized transformation technique for multi-choice linear programming problem. An International Journal of Optimization and Control: Theories \& Applications, 3(1), 45-54 (2013). https://doi.org/10.11121/ijocta. $\underline{01.2013 .00132}$

[14] C. Villani, Topics in optimal transportation. American Mathematical Soc., 2003, no. 58.

[15] P. Dai Pra, "A stochastic control approach to reciprocal diffusion processes," Applied mathematics and Optimization, vol. 23, no. 1, pp. 313-329, 1991. https://doi.org/10.1 $\underline{007 / \mathrm{BF} 01442404}$ 
[16] Y. Chen, T. Georgiou, and M. Pavon, "Optimal steering of a linear stochastic system to a final probability distribution," arXiv preprint arXiv: 1408.2222, 2014.

[17] Y. Chen, T. Georgiou, and M. Pavon, "Optimal steering of a linear stochastic system to a final probability distribution, Part II," arXiv preprint arXiv: 1410.3447, 2014.

[18] T. Mikami and M. Thieullen, "Optimal transportation problem by stochastic optimal control," SIAM Journal on Control and Optimization, vol. 47, no. 3, pp. 1127-1139, 2008. https://doi.org/10.1137/050631264

[19] A. Figalli, Optimal transportation and action-minimizing measures. Publications of the Scuola Normale Superiore, Pisa, Italy, 2008.

[20] Y. Chen, T. Georgiou, and M. Pavon, "A computational approach to optimal mass transport via the Schrodinger bridge problem," " in preparation, 2015.

[21] Gedam V.K. and 2Mahamad B. Pathan, Extended Stochastic Transportation Problem with Flexible Inputs, IOSR Journal of Mathematics (IOSR-JM) e-ISSN: 2278-5728, p-ISSN: 2319-765X. Volume 13, Issue I Ver. V (Jan. - Feb. 2017), PP 48-59

[22] Sankar Kumar Roy, Deshabrata Roy Mahapatra, Mahendra Prasad Biswal, Multi-choice stochastic Transportation problem with exponential distribution, Journal of Uncertain Systems Vol.6, No.3, pp.200-213, 2012

[23] [23] Shvidler, M. and Karasaki, K. 1997, Probability density functions for solute transport in porous media, Abstracts for the AGU Fall Meeting, San Francisco.

[24] Mark Shvidler, Kenzi Karasaki, Probability Density Functions for Solute Transport in Random Field, Transport in Porous Media, March 2003, Volume 50, Issue 3, pp 243-266 https://doi.org/10.1023/A:1021129325701

\section{Authors}

Dr. Mohammad Rashid Hussain, Assistant Professor, Department of Information Systems, College Of Computer Science, King Khalid University, Abha, Kingdom of Saudi Arabia, received his Master of Technology degree from the Department of Computer Science \& Engineering, Anna University, Chennai, India. After that he obtained his PhD degree from Bihar University, India. He was an Associate Professor in the Department of Computer Science \& Engineering, ABESIT Ghaziabad, India. $\mathrm{He}$ is currently working as an Assistant Professor in the department of Information Systems, King Khalid University, Abha, Saudi Arabia. His research interests include Computer Networks, Information Technology and Operation Research Email id: humohammad@kku.edu.sa

Mohammed Qayyum, Lecturer, Department of Computer Engineering, College Of Computer Science, King Khalid University, Abha, Kingdom of Saudi Arabia, Faculty of Computer Engineering, King Khalid University, Saudi Arabia. He worked as an Assistant Professor under the Department of Computer Science and Engineering at MJCET, Hyderabad, India. Prior to that, He also worked as a Systems Engineer with designation as Member Technical Staff for Ikanos Communications Inc. Bangalore, India. He completed his Bachelor of Technology degree in Computer Science \& Engineering and Master of Technology degree in Software Engineering from JNT University, Hyderabad, India. He is keen and desperate for research in MANETS, IoT and Operation Research. Email id: mdqayyum.se@gmail.com 
Mohammad Equebal Hussain, Ph.D Scholar, Department of Computer Science, Suresh Gyan Vihar University, Jaipur, India, received his Master of Technology degree from the Department of Computer Science, Indian Statistical Institute, Kolkata, India. He worked as an Assistant Professor under the Department of Computer Science and Engineering at GCET Greater Noida, India. Prior to that, He also worked as a Software Engineer with HCL Bangalore, India. He completed his Bachelor of Technology degree from NIT Patna, Bihar, India. Presently he is a Research Scholar in Gyan Vihar University, Jaipur, India Email id: mdequebal.60508@mygyanvihar.com

Article submitted 2018-11-23. Resubmitted 2019-01-27. Final acceptance 2019-01-27. Final version published as submitted by the authors. 